\title{
Aortic root and valve surgery after arterial switch operation
}

\author{
Tyson A. Fricke, BMedSci, Christian P. Brizard, MD, Yves d'Udekem, MD, PhD, and
}

Igor E. Konstantinov, $\mathrm{MD}, \mathrm{PhD}$, Melbourne, Australia

Between May 1983 and January 2009, 720 arterial switch operations (ASOs) were performed at the Royal Children's Hospital, Melbourne, Australia (Figure 1). Of those, 618 $(85.8 \%)$ patients had simple transposition of the great arteries (d-TGA), 57 (9.2\%) had Taussig-Bing anomaly, 21 $(3.0 \%)$ had congenitally corrected transposition of the great arteries, $5(0.7 \%)$ had Mustard procedures converted to ASO, $10(1.4 \%)$ had Senning procedures converted to ASO, and the remaining $9(1.3 \%)$ had ASO as part of univentricular repair.

From the Cardiac Surgery Unit, Royal Children's Hospital, University of Melbourne, and Murdoch Children's Research Institute, Melbourne, Australia.

Disclosures: Authors have nothing to disclose with regard to commercial support.

Received for publication May 7, 2012; revisions received June 10, 2012; accepted for publication July 25, 2012; available ahead of print Sept 10, 2012.

Address for reprints: Igor E. Konstantinov, MD, PhD, Royal Children's Hospital, Flemington Rd, Parkville, VIC 3052, Australia (E-mail: igor.konstantinov@rch.org. $\mathrm{au})$.

J Thorac Cardiovasc Surg 2012;144:1269-71

$0022-5223 / \$ 36.00$

Crown Copyright (C) 2012 Published by Elsevier Inc. on behalf of The American

Association for Thoracic Surgery

http://dx.doi.org/10.1016/j.jtcvs.2012.07.038
Of these 720 patients, $15(2.1 \%)$ underwent surgery on the neoaortic root or neoaortic valve after ASO. Surgery occurred at a mean 8.8 years (median, 9.1 years; range, 7 months to 16.8 years) after ASO. Freedom from neoaortic root or valve surgery was $99.5 \%$ (95\% confidence interval [CI], 98.5\%-99.9\%), 99.3\% (95\% CI, 98.2\%-99.7\%), 98.3\% (95\% CI, 96.6\%-99.1\%), 96.7\% (95\% CI, $94.0 \%-98.2 \%)$, and $94.6 \%(95 \%$ CI, 90.6\%-97.0\%) at $1,5,10,15$, and 20 years, respectively, after ASO. Ten of 15 patients $(1.6 \%)$ had primary ASO for d-TGA, $2(20 \%)$ had conversion to ASO after Senning procedure, $1(20 \%)$ had conversion to ASO after Mustard procedure, 1 $(4.8 \%)$ had double switch for congenitally corrected transposition of the great arteries, and $1(11.1 \%)$ had ASO for transposition of the great arteries with univentricular physiology.

Further analysis of patients undergoing ASO for d-TGA $(n=618)$ demonstrated that aortic surgery was rare in patients with intact ventricular septum $(\mathrm{n}=408)$ with $(0 \%$, $0 / 10)$ or without $(1.0 \%, 3 / 398)$ aortic arch obstruction (AAO), but more frequent in those with ventricular septal

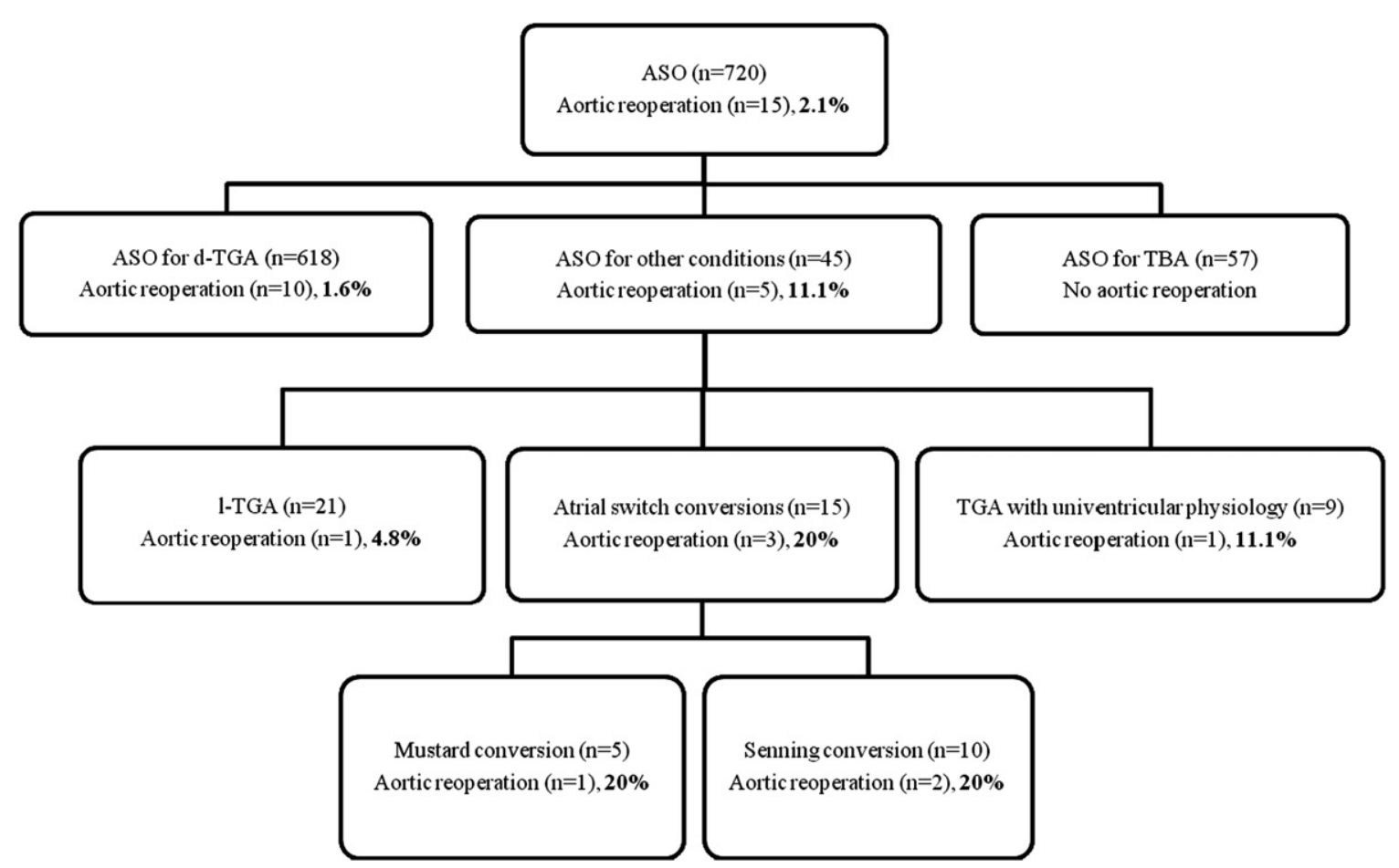

FIGURE 1. Flow chart demonstrating distribution of aortic root and valve surgery in subgroups of patients after arterial switch operation (ASO). TBA, Taussig-Bing anomaly; $T G A$, transposition of great arteries; $d-T G A$, simple transposition of great arteries; $l-T G A$, congenitally corrected transposition of great arteries. 
TABLE 1. Characteristics of patients requiring aortic root or aortic valve surgery after arterial switch operation

\begin{tabular}{|c|c|c|c|c|c|c|}
\hline Patient no. & Anomaly & Age at $\operatorname{ASO}(y)$ & Repair & Aortic surgery & $\begin{array}{c}\text { Age at first aortic }(y) \\
\text { reoperation }\end{array}$ & Time since ASO (y) \\
\hline \multirow[t]{2}{*}{1} & TGA, VSD & $6^{*}$ & ASO & AVR & 11.5 & 11 \\
\hline & & & & Bentall & & 14.5 \\
\hline 2 & TGA, VSD & 14 & Mustard to ASO & AVR & 19.4 & 5.4 \\
\hline 3 & 1-TGA, VSD & 3 & Double switch & AVR & 19.8 & 16.5 \\
\hline 4 & TGA, IVS & $7 \dagger$ & ASO & Bentall & 16.8 & 16.8 \\
\hline 5 & TGA, VSD & 10 & Senning to ASO & AVR & 22.4 & 12.3 \\
\hline 6 & TGA, IVS & $21 \dagger$ & ASO & Bentall & 15.4 & 15.4 \\
\hline \multirow[t]{2}{*}{$7 \ddagger$} & TGA, IVS & $10 \dagger$ & ASO & Ross & 4 & 4 \\
\hline & & & & AVR & & 5 \\
\hline 8 & TGA, VSD & 7 & ASO & VSAAR and AoV repair & 17.4 & 10.5 \\
\hline 9 & TGA, VSD & $5 \dagger$ & ASO & AoV repair & 6.3 & 6.3 \\
\hline 10 & TGA, VSD & $4 \dagger$ & ASO & AoV repair & $7 *$ & $7 *$ \\
\hline 11 & TGA, IVS, COA & $8 \dagger$ & ASO & AoV repair & 9.1 & 9.1 \\
\hline \multirow[t]{3}{*}{12} & TGA, VSD & 5 & Senning to ASO & AoV repair & 5 years & $9 \dagger$ \\
\hline & & & & AVR & & $20 \dagger$ \\
\hline & & & & AVR & & 5 \\
\hline 13 & TGA, VSD, IAA & $2 \dagger$ & ASO & AVR & 8.9 & 8.9 \\
\hline 14 & TGA, VSD & $2^{*}$ & ASO & AoV repair & $11^{*}$ & $8^{*}$ \\
\hline 15 & TGA, VSD, TA, IAA & $16 \dagger$ & ASO & VSAAR & 15 & 15 \\
\hline
\end{tabular}

$\overline{T G A}$, Transposition of great arteries; VSD, ventricular septal defect; $A S O$, arterial switch operation; AVR, aortic valve replacement; Bentall, aortic root replacement with composite graft; $l$-TGA, congenitally corrected TGA; IVS, intact interventricular septum; VSAAR, valve-sparing aortic root replacement; AoV, aortic valve; COA, coarctation of the aorta; IAA, interrupted aortic arch, TA, tricuspid atresia. *Months. †days. ‡deceased.

defect $(\mathrm{n}=210)$ with $(7.1 \%, 2 / 28)$ and without $(2.2 \%$, 4/182) AAO. Ventricular septal defect was not a risk factor for aortic reoperation in this subgroup.

There were 19 surgeries in the 15 patients. There were 8 neoaortic valve replacements, 5 neoaortic valve repairs, 3 Bentall procedures, 1 Ross procedure, 1 valve-sparing neoaortic root replacement, and 1 valve-sparing neoaortic root replacement with concomitant neo-aortic valve repair. Table 1 summarizes the patients and the operations performed.

One of the 15 patients $(6.7 \%)$ died during surgery on the neoaortic root or valve following ASO. This patient had undergone an ASO and concomitant neoaortic valvotomy for TGA at age 10 days. At age 4 years, a Ross procedure was performed because of progressive neoaortic regurgitation. The patient again developed severe neoaortic regurgitation and underwent a neoaortic valve replacement 1 year later. The patient was put on extracorporeal membrane oxygenation on postoperative day 1 , but died 2 days later of cerebral hemorrhage that was confirmed at autopsy.

Follow-up was obtained for all 15 patients. Mean followup time was 14.5 years (median, 16.3 years; range, 4.4-25.5 years) after ASO and a mean 5.7 years (median, 4.3 years; range, 1 month-15.3 years) after surgery on the neoaortic root or valve.

Age at time of ASO $>12$ months was the only risk factor for aortic reoperation on logistic regression multivariate analysis (odds ratio, 9.6; 95\% CI, 3.1-29.5; $P<.001)$.

\section{DISCUSSION}

Despite concern for the neoaortic root function after ASO, reintervention rates on the root or valve remain low. ${ }^{1-5}$ Incidence of aortic valve surgery is estimated at $2 \%$ to $2.5 \%$ at 10 years. ${ }^{1,2} \mathrm{We}$ demonstrated that patients with Taussig-Bing anomaly have higher rates of moderate or worse aortic regurgitation as compared with patients with transposition of the great arteries. ${ }^{4}$ However, none of our 57 patients required neoaortic reoperation. ASO performed as a primary operation for biventricular repair was associated with low incidence of aortic valve or root reoperations, but it was much higher following ASO done for other conditions, especially after conversion of atrial switch operations to ASO. Those patients underwent the ASO at older age. Thus, it is not surprising that children who underwent ASO at age $\geq 1$ year were at increased risk for aortic root or valve reoperation. It appears that aortic valve or root surgery would be required more often in those who underwent concomitant repair of $\mathrm{AAO}$ at the time of the ASO, especially those with interrupted aortic arch. ${ }^{3}$ Although aortic surgery was more frequent in patient with $\mathrm{AAO}$, this did not reach statistical significance, likely due to small number of aortic reoperations in this subgroup. 


\section{CONCLUSIONS}

Surgery on the neoaortic root or valve is rare after ASO and is required predominantly in children older than age 1 year at the time of ASO, particularly those who underwent conversion of the atrial switch.

\section{References}

1. Lange R, Cleuziou J, Hörer J, Holper K, Vogt M, Tassani-Prell P, et al. Risk factors for aortic insufficiency and aortic valve replacement after the arterial switch operation. Eur J Cardiothorac Surg. 2008;34:711-7.
2. Losay J, Touchot A, Capderou A, Piot J-D, Belli E, Planché C, et al. Aortic valve regurgitation after arterial switch operation for transposition of the great arteries: incidence, risk factors, and outcome. J Am Coll Cardiol. 2006;47: 2057-62.

3. Fricke TA, Brizard C, d'Udekem Y, Konstantinov IE. Arterial switch operation in children with interrupted aortic arch: long-term outcomes. J Thorac Cardiovasc Surg. 2011;141:1547-8.

4. Soszyn N, Fricke TA, Wheaton G, Ramsay JM, Brizard CP, Konstantinov IE. Outcomes of the arterial switch operation in patients with Taussig-Bing anomaly. Ann Thorac Surg. 2011;92:673-9.

5. Fricke TA, d'Udekem Y, Richardson M , Thuys C, Dronavalli M, Ramsay JM, et al. Outcomes of the arterial switch operation for transposition of great arteries: 25 years of experience. Ann Thorac Surg. 2012;94:139-45. 